\title{
PENERAPAN KONSEP SAAS (SOFTWARE AS A SERVICE) PADA APLIKASI PENGGAJIAN
}

\author{
Andy Prasetyo Utomo \\ Fakultas Teknik, Program Studi Sistem Informasi \\ Universitas Muria Kudus \\ Email: andyutomo@gmail.com
}

\begin{abstract}
ABSTRAK
Salah satu layanan yang ditawarkan oleh cloud computing adalah Software as a Service (SaaS). SaaS menawarkan sebuah kemudahan, kecepatan efisiensi biaya dalam mengembangkan dan menggunakan software untuk kebutuhan bisnis. Konsep SaaS ini akan diterapkan pada aplikasi penggajian berbasis desktop dengan menggunakan tool VFP2IIS. Prototype aplikasi penggajian yang dihasilkan, dikembangkan dengan menggunakan metode perancangan OOD (Object Oriented Development) dengan tool UML (Unified Modelling Language). Prototype aplikasi yang dihasilkan berbasis WEB dengan menganut konsep SaaS.
\end{abstract}

Kata kunci: SaaS, aplikasi pengajian, OOD, UML.

\section{ABSTRACT}

One of the services offered by cloud computing is a Software as a Service (SaaS). SaaS offers an ease, speed and cost efficiency in developing the use of software for business needs. The SaaS concept will be applied to desktop-based payroll application using tools VFP2IIS. Prototype generated payroll application, developed using design methods OOD (Object Oriented Development) with the tool UML (Unified Modeling Language). The resulting prototype Web-based applications by embracing the concept of SaaS.

Keywords: SaaS, payroll application, OOD, UML.

\section{PENDAHULUAN}

Cloud computing adalah gaya komputasi di mana sumber daya komputasi mudah untuk didapat dan diakses, mudah digunakan, murah, dan langsung dapat dijalankan [1]. Cloud computing adalah sebuah teknologi yang dapat membantu menyelesaikan permasalahan yang berhubungan dengan keterbatasan sumber daya TI. Teknologi ini menggabungkan prinsip dasar ekonomi dan peletakan sumber daya komputasi. Teknologi komputasi ini memiliki beberapa karakteristik, salah satunya adalah penyewaan berbasis penggunaan. Cloud computing adalah paradigma komputasi yang melibatkan outsourcing dari sumber daya komputasi dengan kemampuan untuk melakukan skalabilitas sumberdaya TI, penetapan penggunaan sumber daya sesuai permintaan dengan biaya infrastruktur yang tidak memerlukan investasi TI di muka.

Salah satu layanan yang ditawarkan oleh cloud computing adalah Software as a Service (SaaS). SaaS dapat digunakan sebagai wahana baru dalam pembiayaan dan pemakaian sumber daya teknologi informasi [2]. Dengan menggunakan konsep SaaS, user sebagai pengguna software dapat langsung menggunakan dan memanfaatkan software tersebut tanpa harus mengeluarkan biaya pengembangan atau pengadaan terlebih dahulu. Selain itu pengguna juga hanya membayar biaya sewa selama masih menggunakan software tersebut. Dari sisi hardware yang digunakan untuk mendukung jalannya software, pengguna tidak perlu memikirkan biaya pengadaan dan perawatannya, karena semua sudah ditanggung oleh pihak vendor atau penyedia jasa layanan cloud.

Berdasarkan latar belakang diatas, pada jurnal ini peneliti akan mempublikasikan hasil penelitian mengenai penerapan salah satu konsep layanan cloud computing yang berhubungan dengan software yaitu SaaS pada aplikasi penggajian. 


\section{METODOLOGI PENELITIAN}

Sejalan dengan tujuan yang ingin dicapai dalam penelitian ini, yakni penerapan konsep SaaS pada aplikasi penggajian, maka penelitian ini dilakukan dengan menggunakan kajian terhadap model aplikasi penggajian yang sudah ada, kemudian berdasarkan hasil kajian itu dirumuskan satu analisis dan desain sistem untuk mengembangkan model yang sudah ada tersebut ke dalam model aplikasi penggajian baru yang menganut konsep SaaS. Tahapan penelitian ditunjukkan pada gambar 1.

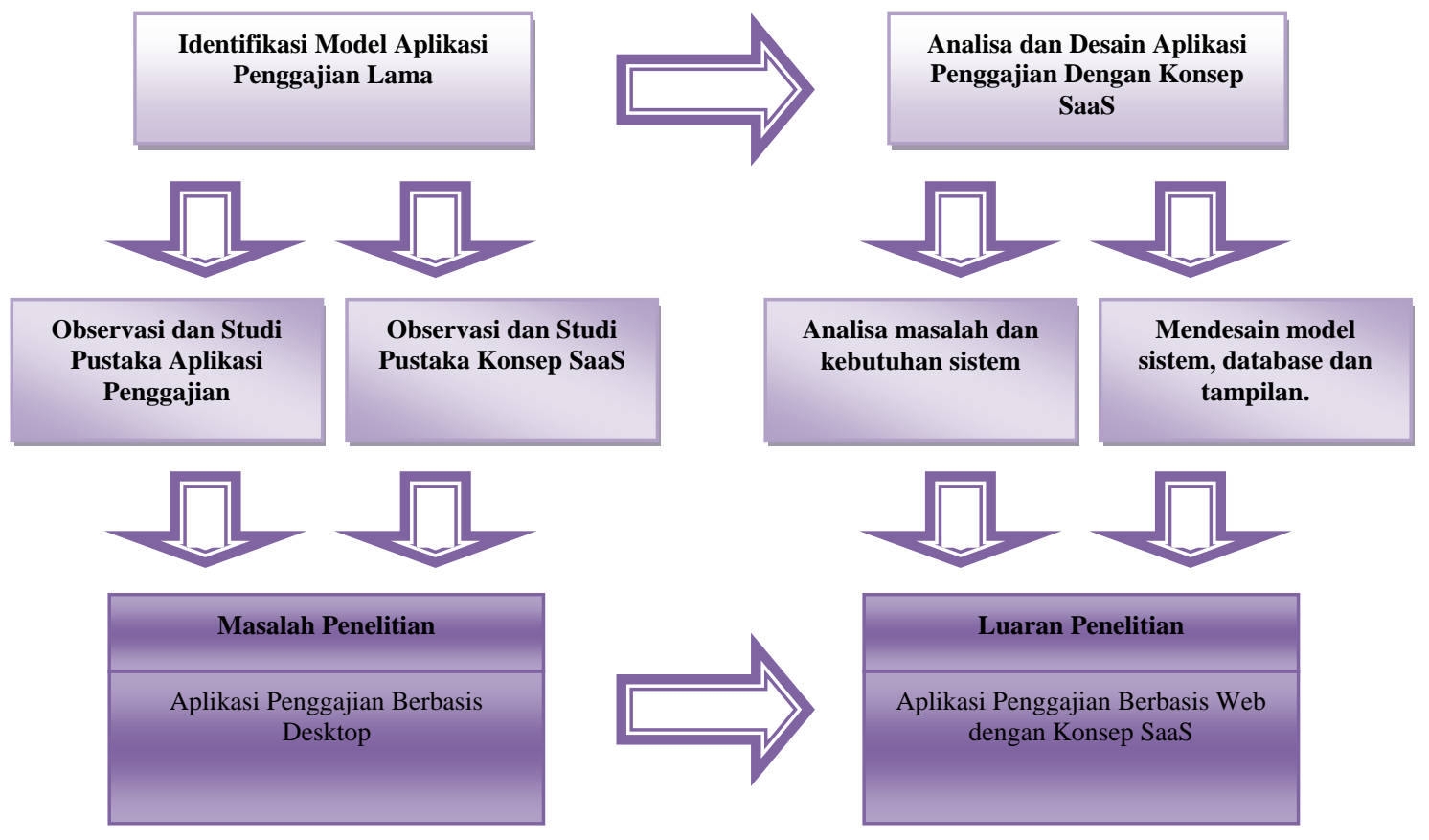

Gambar 1. Tahapan penelitian

Lokasi penelitian dilakukan di laboratorium rekayasa perangkat Lunak, Program Studi Sistem Informasi Fakultas Teknik Universitas Muria Kudus. Desain model yang digunakan dalam mengembangkan aplikasi penggajian yang menganut konsep SaaS adalah menggunakan perancangan OOD (Object Oriented Desain) dan tool yang digunakan adalah Unified Modelling Language (UML). OOD adalah metode yang membawa kita ke dekomposisi berorientasi objek. Dengan menerapkan desain berorientasi objek, kita dapat menciptakan perangkat lunak yang tangguh dengan meminimalisasi penulisan ekspresi serta mengurangi risiko yang melekat dalam pengembangan sistem perangkat lunak yang kompleks. [3]. Desain model yang termasuk di dalam UML adalah use case diagram, class diagram, sequence diagram, activity diagram, state diagram, collaboration diagram.

Pada penelitian ini yang dijadikan sebagai variable operasional adalah konsep SaaS, konsep SaaS ini nantinya akan diamati dan dilakukan observasi atau pengukuran secara cermat terhadap objek atau fenomena tersebut. Variabel SaaS ini nantinya akan diukur untuk dapat ditentukan karakteristiknya.

Penelitian ini masuk dalam jeni penelitian deskriptif kualitatif, yaitu serangkaian kegiatan atau proses untuk mengungkapkan proses - proses informasi dalam konsep SaaS yang digunakan sebagai dasar dalam perancangan sistem informasi dengan menerapkan tahap-tahap yang ada dalam SDLC (System Development Life Cycle).

Sampel merupakan bagian dari populasi yang ingin diteliti, dipandang sebagai suatu pendugaan terhadap populasi, namun bukan populasi itu sendiri. Sampel dianggap sebagai perwakilan dari populasi yang hasilnya mewakili keseluruhan gejala yang diamati. Pada penelitian ini sampel yang digunakan adalah sebuah aplikasi penggajian yang nantinya akan dijadikan sebagai bahan utama dalam penelitian ini. Data primer adalah data yang diperoleh langsung baik melalui pengamatan, pencatatan atau penelitian terhadap obyek penelitian yaitu aplikasi penggajian. Data Sekunder adalah data yang diperoleh secara tidak langsung yaitu melalui dokumentasi data dari buku-buku literatur mengenai konsep SaaS di dalam cloud computing. 


\section{HASIL PENELITIAN DAN PEMBAHASAN}

Dengan menggunakan konsep SaaS, aplikasi penggajian yang dikembangkan bisa digunakan secara privat oleh banyak pengguna. Aplikasi penggajian tersebut juga bisa diakses di banyak tempat yang mempunyai koneksi ke jaringan internet. Salah satu syarat untuk dapat mengadopsi konsep SaaS adalah aplikasi yang dikembangkan haruslah berbasis web. Model aplikasi penggajian yang awalnya berbasis desktop yang dikembangkan dengan bahasa pemrograman Visual Foxpro pada penelitian ini akan coba dijalankan melalui browser dengan menggunakan tool VFP2IIS.

VFP2IIS adalah komponen yang memungkinkan pengembang untuk dapat menjalankan aplikasi yang dibangun dengan Visual FoxPro kedalam browser Internet Explorer. VFP2IIS menyediakan sebuah antarmuka antara Visual FoxPro dan Internet Explorer. VFP2IIS adalah middleware yang dapat menciptakan HTML secara otomatis dari project aplikasi yang dibangun dari Visual Foxpro. Semua desain dan penulisan kode program dapat dilakukan di VFP. Dengan menggunakan VFP2IIS, pengembang dapat mengembangkan aplikasi untuk desktop dan WEB dalam satu proyek.

Hasil dari pengembangan aplikasi penggajian yang menerapkan konsep SaaS kemudian dituangkan ke dalam model sistem dalam bentuk diagram pengguna, rincian struktur penyimpanan data dan tampilan antarmuka aplikasi yang akan dihasilkan.

\subsection{Diagram Use Case}

Use case adalah spesifikasi dari kumpulan aksi yang dijalankan oleh sistem [4]. Diagram use case untuk aplikasi penggajian yang menerapkan konsep SaaS di tunjukkan pada gambar 2.

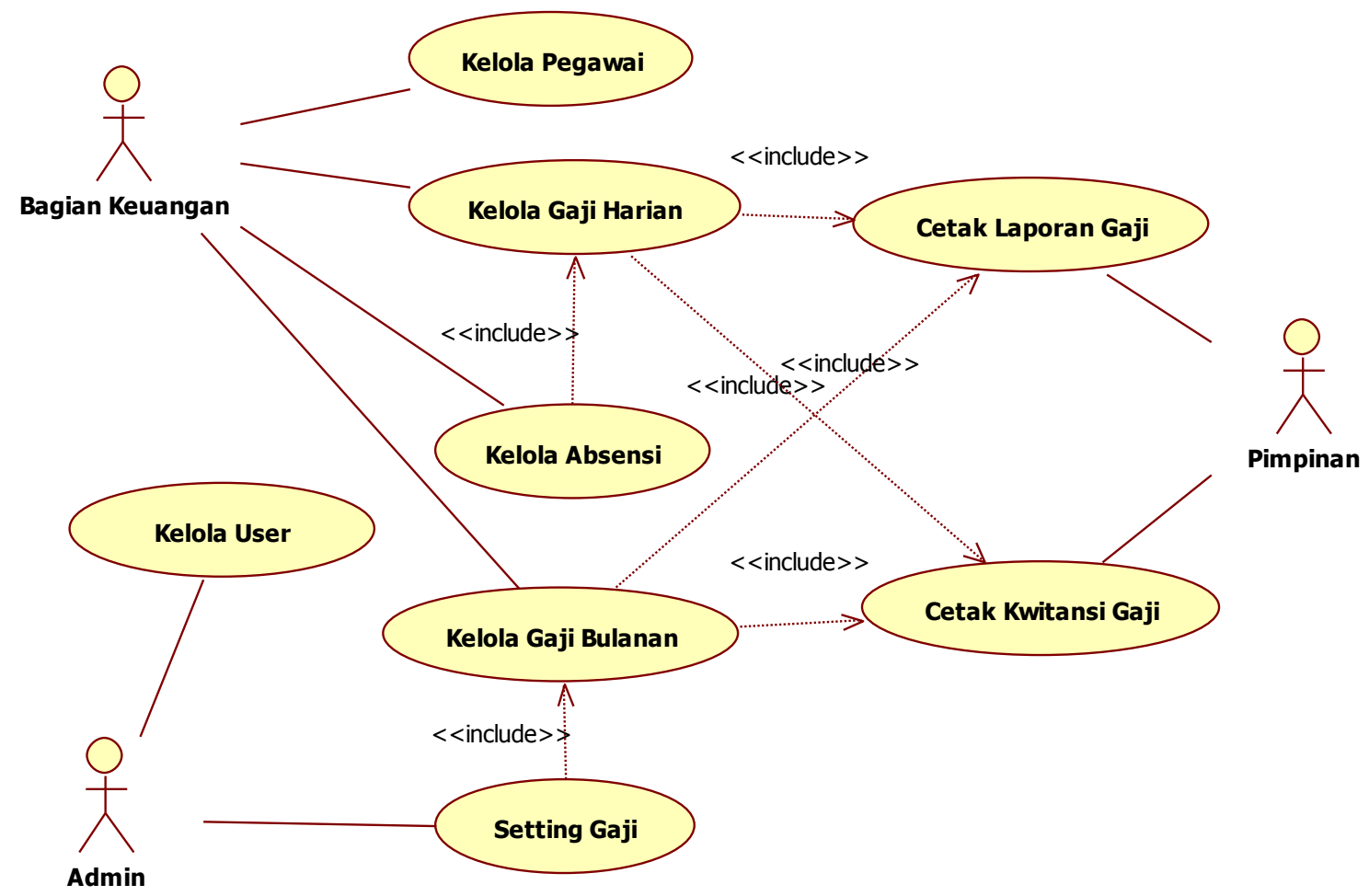

Gambar 2. Use Case Aplikasi Penggajian 


\subsection{Struktur Tabel Penyimpanan Data}

Aplikasi database yang digunakan untuk mengembangkan aplikasi adalah database foxpro. Terdapat 4 tabel yang saling berelasi yang ditunjukkan pada gambar 4 dan tiga tabel yang bersifat free tabel yang berguna untuk melakukan penyimpanan pengaturan seperti yang ditunjukkan pada gambar 3 .

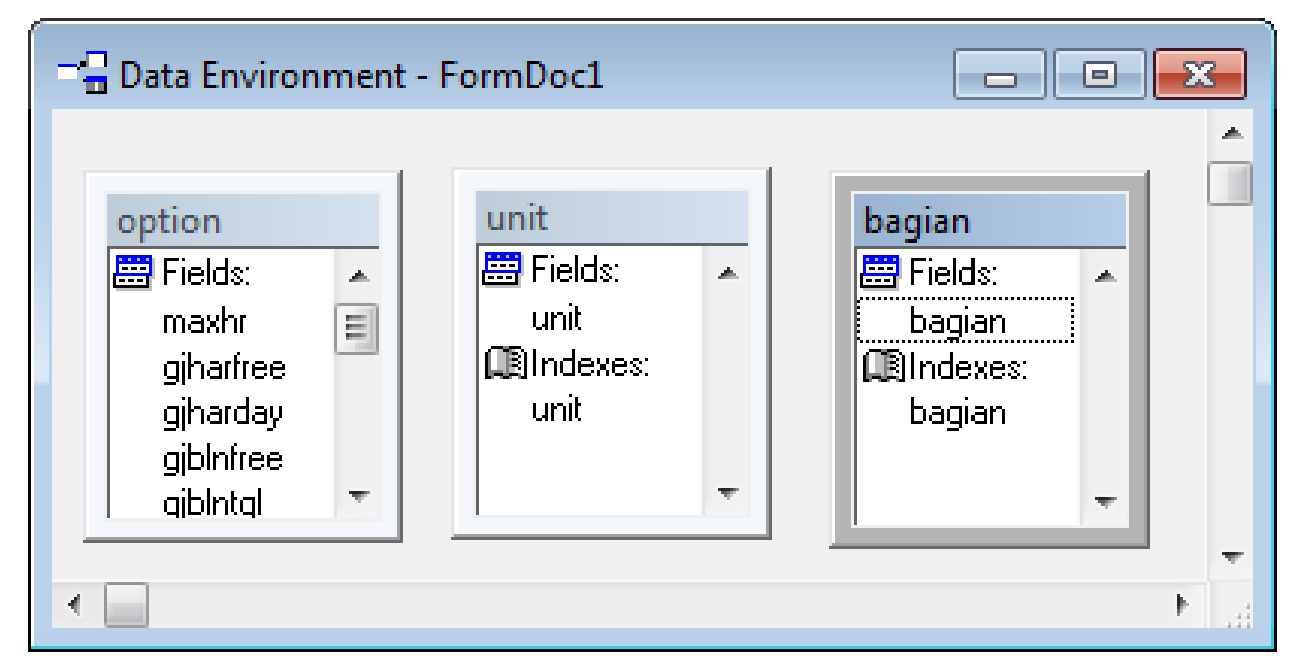

Gambar 4. Free Tabel pada Aplikasi Penggajian

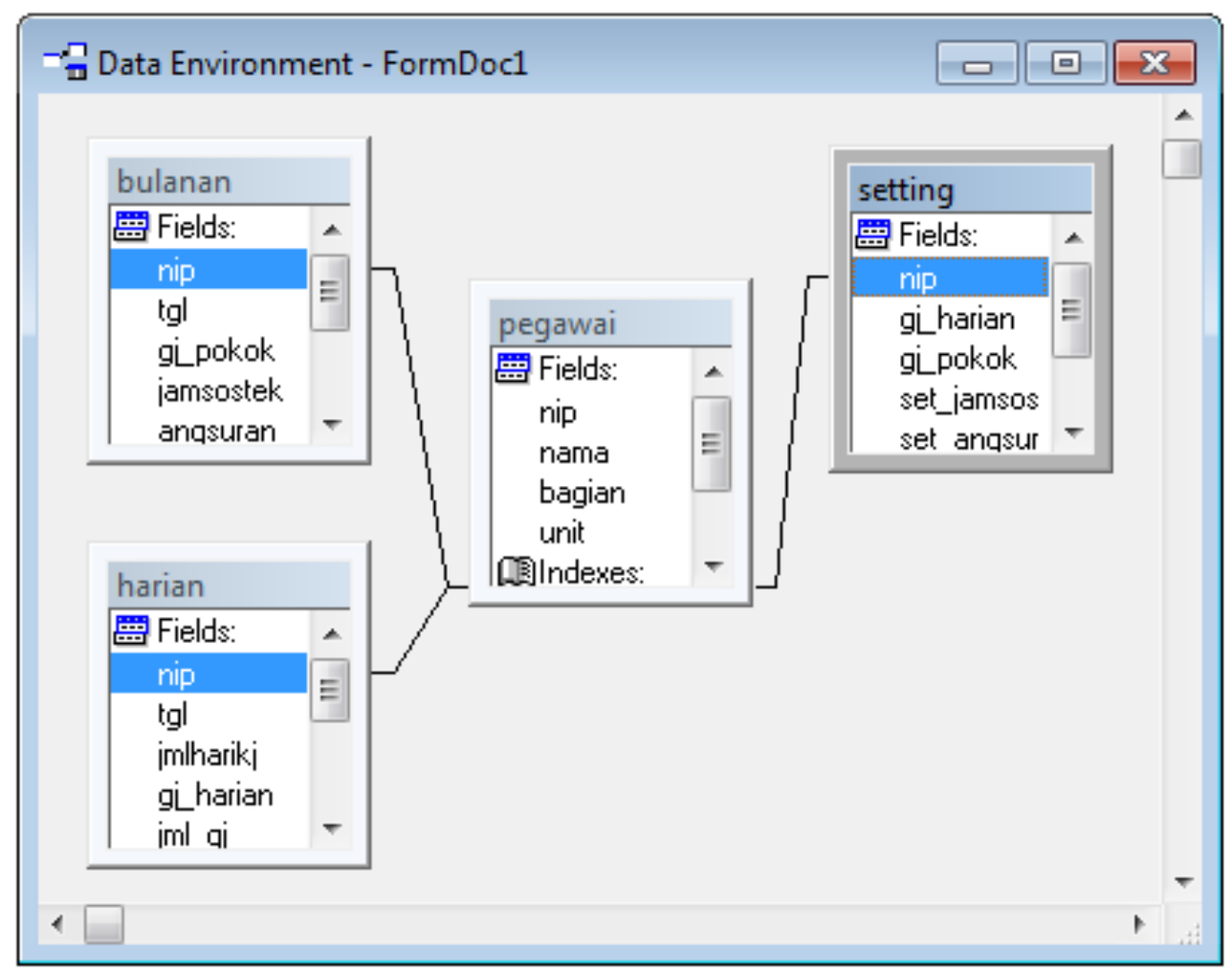

Gambar 4. Skema Relasi Tabel Aplikasi Penggajian 


\subsection{Tampilan antarmuka aplikasi}

Aplikasi penggajian dibangun berbasiskan WEB dengan menggunakan bahasa pemrograman Visual Foxpro dengan memanfaatkan tool VFP2IIS untuk menterjemahkan kode program di Visual Foxpro ke dalam HTML sehingga bisa ditampilkan melalui browser. Pada gambar 5 ditunjukkan salah satu tampilan antarmuka dari aplikasi penggajian yang telah dikembangkan.

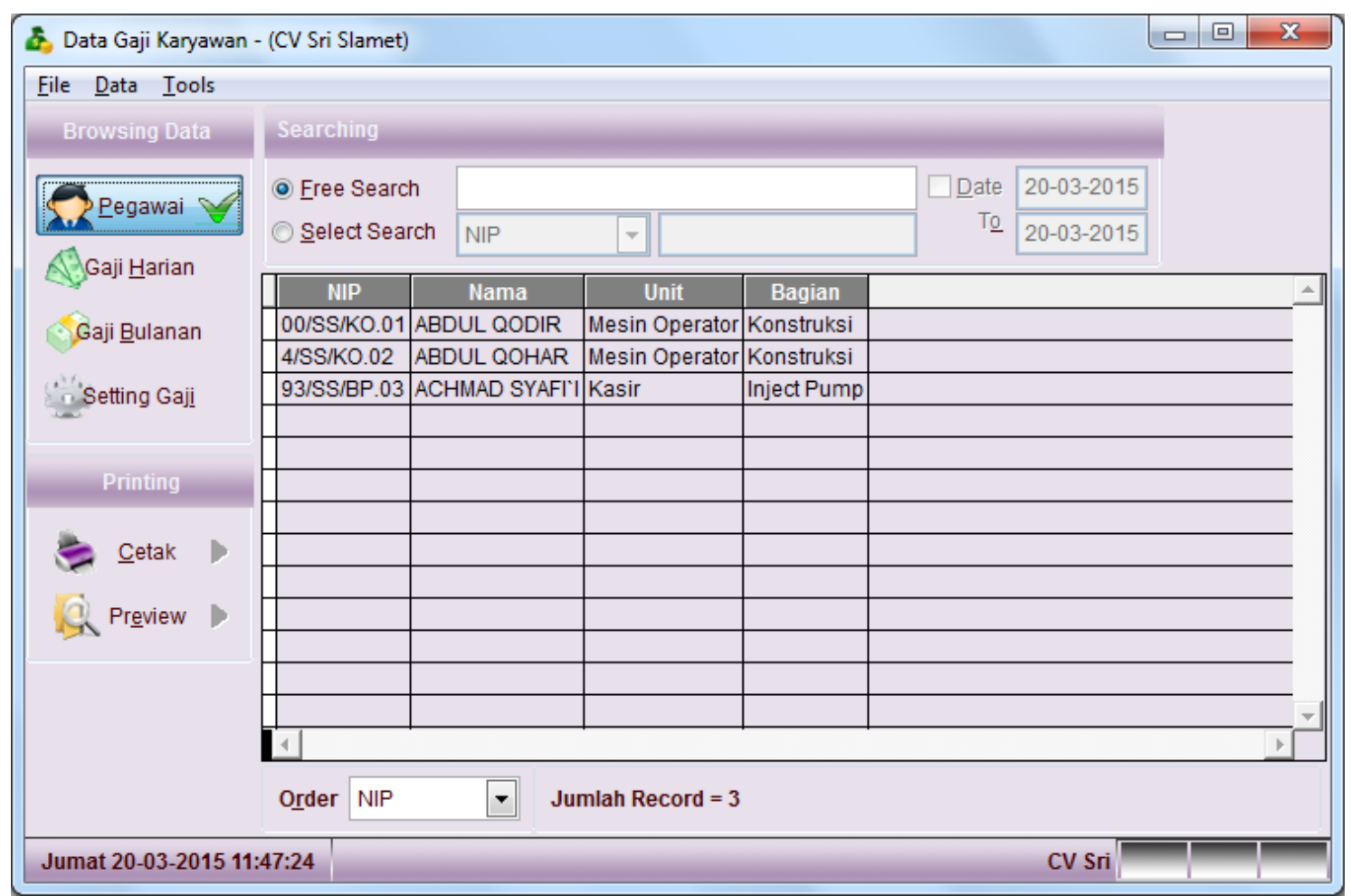

Gambar 5. Tampilan antar muka aplikasi penggajian dengan konsep SaaS

\section{KESIMPULAN}

Dari penelitian yang sudah dilakukan dapat diambil kesimpulan bahwa dengan menggunakan tool VFP2IIS dapat dihasilkan sebuah aplikasi berbasis WEB dari sebuah project aplikasi berbasis desktop dengan bahasa pemrograman Visual Foxpro. Sebuah aplikasi yang menganut konsep SaaS harus berbasis WEB dan dapat digunakan secara privat oleh banyak user melalui jaringan internet. Aplikasi lama berbasis desktop dapat digunakan untuk menerapkan konsep SaaS.

\section{DAFTAR PUSTAKA}

[1] Marks, E. A., \& Lozano, B. (2010). Executive's Guide to Cloud Computing. Canada: John Wiley \& Soons.

[2] Wyld, D. C. (2009). The Utility Of Cloud Computing As A New Pricing And Consumption Model For Information Technology. International Journal of Database Management Systems (IJDMS), 1-20.

[3] Booch, Grady,. Maksimchuk, Robert A., Engle, Michael W., Young, Bobbi J., Conallen, Jim,. Houston, Kelli A., (2007), Object-Oriented Analysis and Design with Applications. Pearson Education, Inc, USA. 
[4] Ibrahim, Noraini., Ibrahim, Rosziati., Saringat, Mohd Zainuri., Mansor, Dzahar., and Herawan, Tutut., (2011), Consistency Rules between UML Use Case and Activity Diagrams Using Logical Approach, International Journal of Software Engineering and Its Applications, vol 5 no 2, pp. 119-134. 